2016-10-15

\title{
Co-located wind and wave energy farms: Uniformly distributed arrays
}

\author{
Astariz, S
}

http://hdl.handle.net/10026.1/8709

10.1016/j.energy.2016.07.069

Energy

All content in PEARL is protected by copyright law. Author manuscripts are made available in accordance with publisher policies. Please cite only the published version using the details provided on the item record or document. In the absence of an open licence (e.g. Creative Commons), permissions for further reuse of content should be sought from the publisher or author. 
"This is the author's accepted manuscript. The final published version of this work (the version of record) is published by Elsevier B.V. in Energy 15 October 2016 available at: $\mathrm{http}: / / \mathrm{dx}$.doi.org/10.1016/i.energy.2016.07.069. This work is made available online in accordance with the publisher's policies. Please refer to any applicable terms of use of the publisher."

\title{
Co-located wind and wave energy farms: uniformly distributed arrays
}

\author{
S. Astariz ${ }^{\mathrm{a} 1}, \mathrm{G}$. Iglesias $^{\mathrm{b}}$ \\ ${ }^{a}$ University of Santiago de Compostela, EPS, Hydraulic Eng., Campus Univ. s/n, 27002 Lugo, \\ Spain. \\ ${ }^{b}$ Plymouth University, School of Marine Science and Engineering, Plymouth PLA 8AA, UK.
}

\begin{abstract}
Co-located wave and wind energy farms can serve to tackle one of the downsides of offshore wind energy relative to its onshore counterpart: the longer non-operational periods. These are partly caused by delays to maintenance tasks due to energetic sea states preventing access. By co-locating Wave Energy Converters (WECs) in an appropriate configuration it may be possible to reduce the wave heights within the wind farm area (shielding effect) and thereby increase the weather windows for maintenance. Previous works analysed the improvements in accessibility obtained by configuring the co-located WECs as a peripheral barrier or interspersed within the farm. However, the former led to an insufficient wave height reduction as the distance to the barrier increased and the latter presented other handicaps, notably in respect of the submarine cable installation and the navigation of workboats. The objectives of this work are: (i) to analyse whether a uniformly distributed array may be more convenient in these respects and (ii) to carry out a comparative economic assessment. This investigation is carried out through a case study at the Horns Rev 1 wind farm by means of a high-resolution spectral wave model. Annual cost savings of up to $900,000 €$ are found.
\end{abstract}

\footnotetext{
${ }^{1}$ Corresponding author; email: sharay.astariz@usc.es; tel.: +34982823295; fax: +34982285926
} 
Keywords: Wave energy; Wind energy; Co-located wind-wave farm; Shadow effect; Weather windows for O\&M; Levelised cost.

\section{Nomenclature}

$A_{\mathrm{TR}}:$ rated power of transformer (MVA)

$A W T_{k}$ : percentage of Accessible Wind Turbines during the $k$ percentage of time

$b$ : the pile spacing $(\mathrm{m})$

$c_{x}$ : spatial velocities in the $x$ component $\left(\mathrm{ms}^{-1}\right)$

$c_{y}$ : spatial velocities in the $y$ component $\left(\mathrm{ms}^{-1}\right)$

$c_{t:}:$ transmission coefficient of the offshore wind turbines

$c_{\theta}:$ rate of change of group velocity which describe the directional rate of turning

$c_{\sigma}$ : rate of change of group velocity which describe the frequency shifting due to changes in currents and water depth

$C_{d}$ : drag coefficient of the piles

$C_{\text {cable }}:$ cost of the electricity transmission cable $(€ / \mathrm{m})$

$C_{M V / H V}:$ cost of the MV/HV transformer $(\mathrm{k} €)$

$C_{t}:$ total costs $(€)$

CALM: Catenary Anchor Leg Mooring

$d:$ depth (m) 
$D$ : distance between the twin bows of a single WaveCat WEC

$D_{c}$ : catenary diameter $(\mathrm{m})$

$D_{p}$ : pile diameter $(\mathrm{m})$

EMODnet: European Marine Observation and Data Network

ERDF: European Regional and Development Fund

$H_{i}$ : incident significant wave height (m)

$H_{s}$ : significant wave height $(\mathrm{m})$

$H_{s i}$ : significant wave height incident on the $i$-th turbine in the baseline scenario without WECs $(m)$

$H_{s, W E C i}$ : significant height incident on the $i$-th turbine with co-located WECs (m)

$H R A_{j}$ : significant wave Height Reduction along the $j$-th Area of wind turbines with colocated WECs

$H R F$ : wave Height Reduction within the Farm with co-located WECs (m)

$I_{n,}$ : maximal current in the medium voltage cable (A)

$J_{\text {farm }}$ : average power output of all co-located WECs $(\mathrm{W} / \mathrm{m})$

$J_{W, i}$ : power production of the $i$-th WEC $(\mathrm{W} / \mathrm{m})$

$J_{W E C}$ : average power production per WEC generated by the co-located $(\mathrm{W} / \mathrm{m})$

$k$ : percentage of time during which the wind turbines are accessible

$K$ : constant with a value $0.02 \mathrm{~kg} /\left(\mathrm{m} \cdot \mathrm{mm}^{2}\right)$ for studless chain and $0.0219 \mathrm{~kg} /\left(\mathrm{m} \cdot \mathrm{mm}^{2}\right)$ for stud-link chain

$m$ : number of turbines in the $j$-th area

$n$ : total number of wind turbines

$n_{W}:$ total number of WECs 
$N$ : wave action density spectrum (Js)

NDA: Non-uniformly Distributed Array

$L:$ total length of the catenary $(\mathrm{m})$

LCOE: Levelised Cost of Energy

$O_{t}:$ electricity generation (MWh)

O\&M: Operation \& Maintenance

PDA: Peripherally Distributed Array

PTO: Power Take-off System

$r$ : discount rate

$S_{\text {tot: }}$ : energy density source terms which describe local changes to the wave spectrum (Js

1)

SWAN: Simulating WAves Nearshore

$t$ : a point in time

$T:$ total number of time points considered

$T_{p}:$ peak wave period (s)

$U_{w}$ : wind speed at $10 \mathrm{~m}$.

UDA: Uniformly Distributed Array

$W_{C A L M}$ : weight of the mooring system $(\mathrm{N})$

WEC: Wave Energy Converter

WF: Wind Farm

$\alpha$ : cost coefficient to calculate the electricity transmission cable that depends on the operating voltage of the cable $(€ / \mathrm{m})$ 
$\beta$ : cost coefficient to calculate the electricity transmission cable that depends on the operating voltage of the cable $(€ / \mathrm{m})$

$\gamma$ : cost coefficient to calculate the electricity transmission cable that depends on the operating voltage of the cable (1/A)

$\theta_{\text {wave }}:$ wave direction $\left(^{\circ}\right)$

$\theta_{\text {wind }}:$ wind direction $\left({ }^{\circ}\right)$

\section{Introduction}

Recently, at the Paris climate conference (COP21) in December 2015, 195 countries adopted the first-ever universal, legally binding global climate deal. The agreement set out a global action plan to put the world on track to avoid dangerous climate change by limiting global warming. In this context, reducing carbon emissions and, therefore, finding alternatives to fossil fuels is fundamental. Marine energy is regarded as a promising energy source due to the vast resource available around the world [1-8]. Already well established commercially, offshore wind energy is the most developed marine renewable, with a relatively mature technology [9-11]. Tidal [12-14] and wave energy $[15,16]$ are less developed. Notwithstanding their environmental benefits, these renewables have to be economically competitive if they are to attract significant investment [17]. Offshore wind energy has a greater resource and better availability than its onshore counterpart [18-21]; on the minus side, it involves higher initial investments and maintenance costs [22-23]. Comparatively frequent maintenance is required in the harsh marine environment [24], yet access to the turbines by workboats the most cost-effective access system [22] - is only possible when the significant wave height is below $1.5 \mathrm{~m}[22,25,26]$. The resulting downtime [27-30] causes significant costs and raises the power output variability, all of which may hamper the development of offshore wind. 
In this context, the co-location of Wave Energy Converters (WECs) in a wind farm [31] has emerged as a solution to increase the accessibility to the wind turbines: the colocated WECs extract energy from the incident waves [32], reducing wave heights in their lee $[33,34]$ and, consequently, improving the accessibility to the wind turbines [3537]. Moreover, other synergies between offshore wind and wave energy can be realised through the co-located WECs $[35,38]$, including a more sustainable use of the scarce marine space [39], a reduction in the intermittency inherent to renewables $[40,41]$ or the opportunity to reduce costs by sharing some of the most expensive elements of an offshore project $[34,42]$.

Within these co-located arrays, different options may be considered [43]: (i) a Peripherally Distributed Array (PDA), where WECs are placed along the perimeter of the wind farm, forming a barrier; (ii) a Uniformly Distributed Array (UDA), with WECs deployed uniformly throughout the wind farm; or (iii) a Non-uniformly Distributed Array (NDA). Previous studies [31, 44] demonstrated that co-located farms increase considerably the accessibility to the wind turbines for maintenance. However, in the first case (PDA array) the wave height reduction achieved in the area farthest from the barrier of WECs was not enough to ensure an appropriate level of accessibility [45]. The NDA configuration, with part of the WECs forming a peripheral barrier and the remaining WECs interspersed between the wind turbines to counter wave regeneration by diffracted energy overcomes this downside, resulting in a more uniform wave height reduction [46]. However, this configuration presents other shortcomings, notably in relation to the installation of the moorings and submarine cables and the manoeuvrability of workboats for access to wind turbines and WECs, which are not facilitated by the non-uniform layout [47]. 
With this in view, the aim of this work is to assess the option of uniformly distributed arrays (UDAs), and in particular to determine whether this configuration may achieve similar values of wave height reduction while facilitating the circulation through the farm. For this purpose, a case study at the Horns Rev offshore wind farm is carried out in which four UDA layouts are considered. A third-generation wave model, SWAN (Simulating WAves Nearshore) and real (observed) wave data are used for estimating the wave conditions within the farm.

This paper is structured in four steps. First, on the basis of previous results obtained at Horns Rev 1 with PDA and NDA configurations, four UDA configurations are proposed and tested for a representative sea state. Second, the two best configurations are simulated with real annual sea data by means of the wave model. Third, the results obtained are analysed in terms of wave height reduction within the wind farm area and power production by means of indicators defined $a d$ hoc. These results are then translated into monetary terms by means of the levelised cost. Finally, the results for the UDA co-located farms are compared with those for PDAs and NDAs, and conclusions are drawn.

\section{Methodology}

\subsection{Study area}

The assessment of the UDAs was carried out by considering an offshore wind farm currently in operation: Horns Rev 1. Located off the Danish North Sea coast (Figure 1), the water depth and distance to shore are in the ranges 6-14 $\mathrm{m}$ and 14-20 km, respectively. Horns Rev 1 is composed by 80 turbines (Vestas V80-2MW) with a monopile substructure erected on a grid of 10 rows [48-49]. The distance between the 
individual wind turbines and rows is $560 \mathrm{~m}$, occupying an area of $21 \mathrm{~km}^{2}$. The wind turbines are ordered on a Cartesian grid (Figure 2).

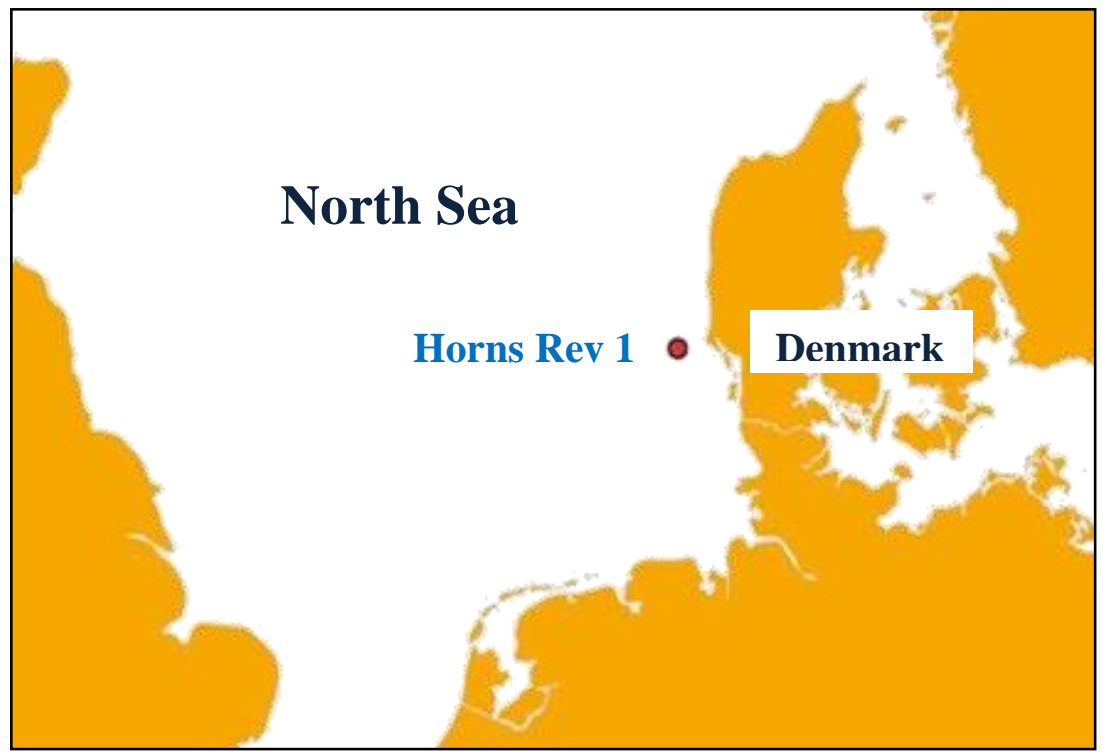

Figure 1. Horns Rev 1 wind farm location.

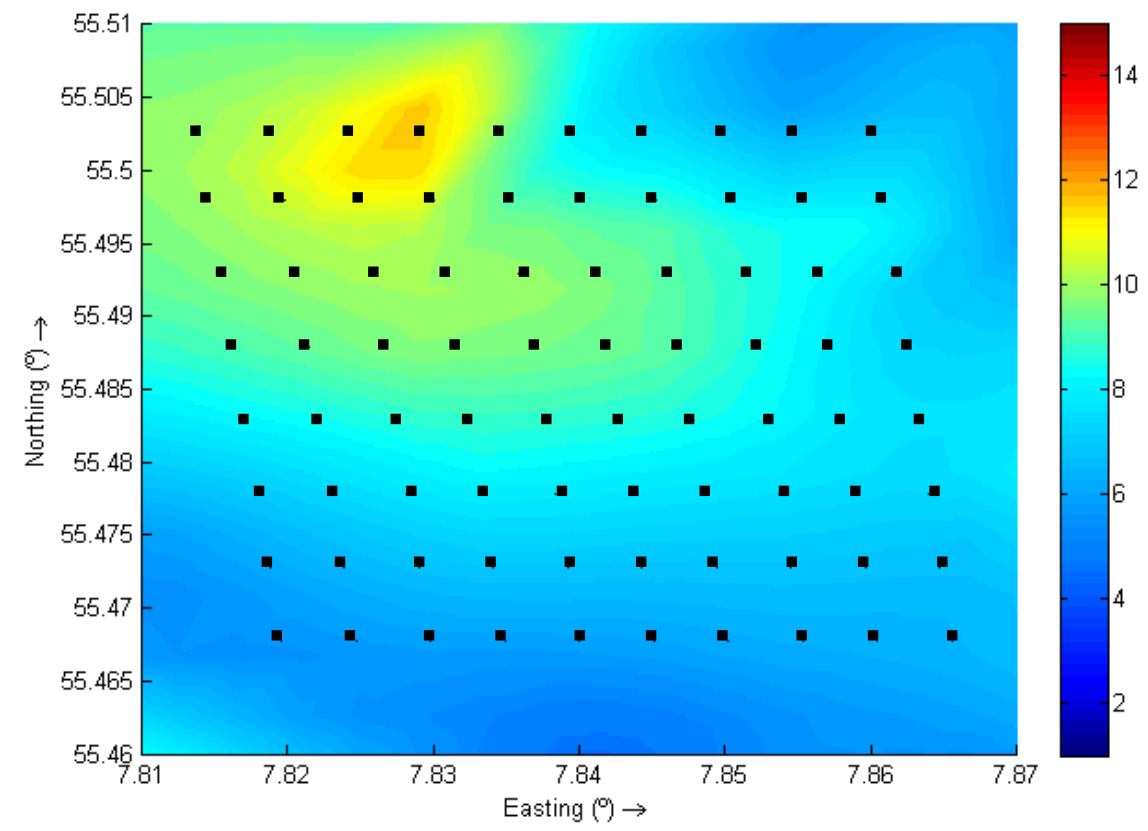

Figure 2. Horns Rev 1 wind farm layout. The colour scale represents the water depth [in $\mathrm{m}]$.

\subsection{Wave and wind climate}


Hindcast data from WaveWatch III, a third-generation offshore wave model, were used in conjunction with wave buoy measurements from May 2012 to April 2013. The main wave climate characteristics are shown in Table 1 and Figure 3. Westerly waves, from the III and IV quadrants, prevail, and the mean significant wave height is $1.49 \mathrm{~m}$. The prevailing wind direction is northerly, from the I and IV quadrants, and the mean wind speed is $8.40 \mathrm{~m} / \mathrm{s}$ (Table 1 ). On the basis of the relatively low inter-annual variability of wave power in the northern part of the North Sea [50] the results can be extended to the present.

Table 1. Main wave and wind statistics Horns Rev 1 from May 2012 to April 2013. $H_{s}$ is the significant wave height, $T_{m 01}$ the mean wave period, $\theta_{\text {wave }}$ the wave direction, $U_{w}$ the wind speed at a height of $10 \mathrm{~m}$ above the sea, and $\theta_{\text {wind }}$ the wind direction.

\begin{tabular}{|c|c|c|c|c|c|c|}
\hline & & $H_{s}(\mathrm{~m})$ & $T_{m 01}(\mathrm{~s})$ & $\theta_{\text {wave }}\left({ }^{\circ}\right)$ & $U_{w}\left(\mathrm{~ms}^{-1}\right)$ & $\theta_{\text {wind }}\left({ }^{\circ}\right)$ \\
\hline \multicolumn{2}{|l|}{ Mean } & 1.49 & 5.84 & 228.97 & 8.40 & 171.55 \\
\hline \multicolumn{2}{|l|}{ Median } & 1.38 & 5.72 & 245.91 & 8.28 & 168.95 \\
\hline \multicolumn{2}{|l|}{ Std. deviation } & 0.81 & 1.66 & 92.56 & 3.52 & 111.67 \\
\hline \multicolumn{2}{|l|}{ Minimum } & 0.09 & 2.36 & 0.02 & 0.02 & 0.24 \\
\hline \multicolumn{2}{|l|}{ Maximum } & 5.41 & 16.05 & 359.97 & 22.21 & 360.00 \\
\hline \multirow{11}{*}{ Percentiles } & 10 & 0.52 & 3.84 & 81.32 & 3.84 & 27.79 \\
\hline & 20 & 0.73 & 4.46 & 138.37 & 5.27 & 53.80 \\
\hline & 25 & 0.83 & 4.72 & 176.38 & 5.79 & 68.29 \\
\hline & 30 & 0.93 & 5.02 & 212.06 & 6.38 & 82.16 \\
\hline & 40 & 1.14 & 5.38 & 231.36 & 7.40 & 126.39 \\
\hline & 50 & 1.38 & 5.72 & 245.91 & 8.28 & 168.95 \\
\hline & 60 & 1.61 & 6.16 & 266.51 & 9.21 & 198.63 \\
\hline & 70 & 1.91 & 6.60 & 291.95 & 10.16 & 241.05 \\
\hline & 75 & 2.03 & 6.79 & 309.00 & 10.78 & 280.07 \\
\hline & 80 & 2.19 & 6.96 & 319.53 & 11.42 & 306.56 \\
\hline & 90 & 2.62 & 7.53 & 328.64 & 13.11 & 330.58 \\
\hline
\end{tabular}



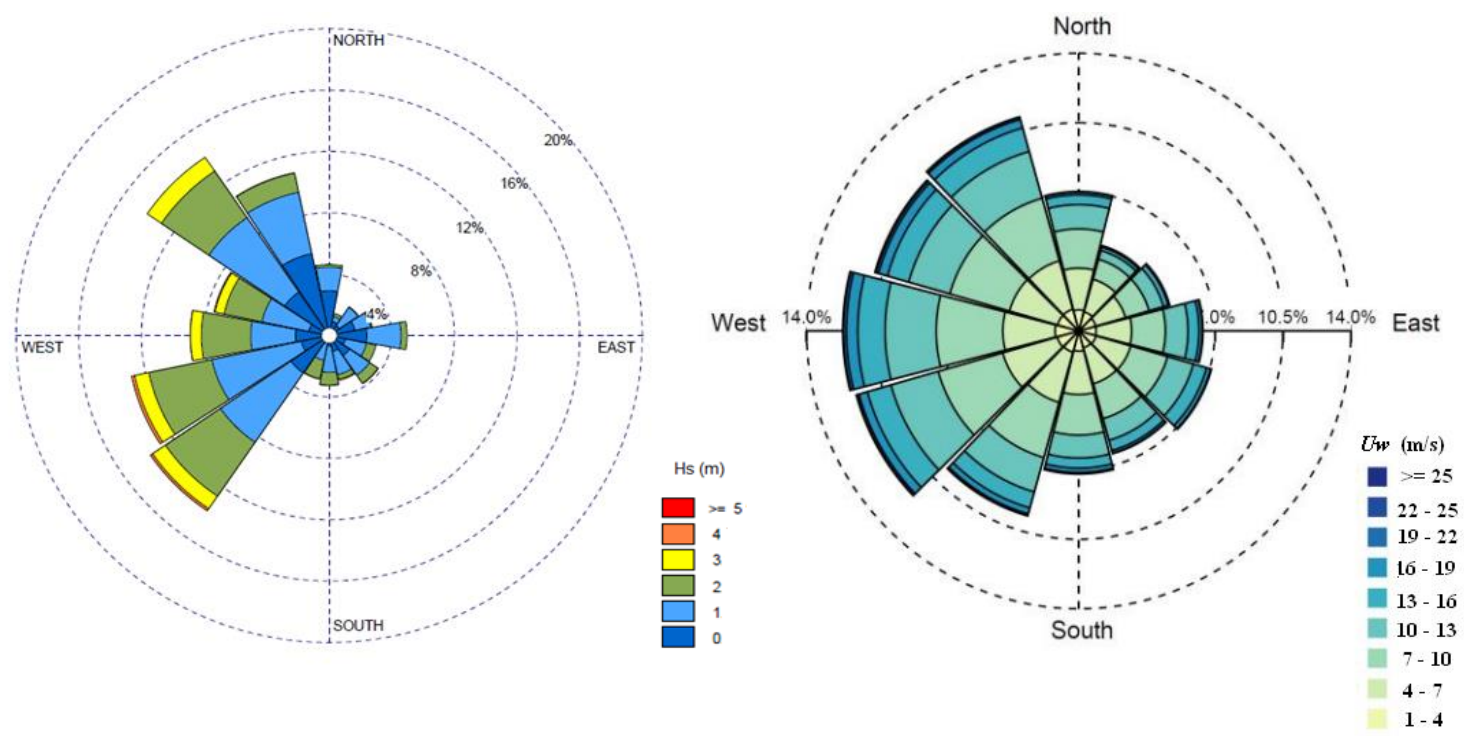

Figure 3. Significant wave height $\left(H_{s}\right)$ [left] and wind speed $\left(U_{w}\right)$ [right] roses at the study site.

On these grounds, a representative case study with a significant wave height $\left(H_{s}\right)$ of 2 $\mathrm{m}$, a mean period $\left(T_{m 01}\right)$ of $5.5 \mathrm{~s}$ and $270^{\circ}$ as the predominant wave direction $\left(\theta_{\text {wave }}\right)$ was defined for a first assessment of the effectiveness of the UDA configurations in reducing the wave height below the workboat threshold $(1.5 \mathrm{~m})$.

\subsection{Co-located farm layouts}

The WEC device used in all cases studies was WaveCat: a floating offshore WEC whose principle of operation is wave overtopping [51]. The wave transmission coefficient was based on the laboratory tests carried out with a model at a 1:30 scale to determine the wave field-WEC interaction [52]. The nominal power at 1:1 scale is expected to be 1.2 MW [53]. As for the configuration of the devices, the minimum spacing between devices is $2.2 D$, where $D=90 \mathrm{~m}$ is the distance between the twin bows of a single WaveCat WEC [54].

The UDAs were laid out based on the results obtained for PDA [45, 55] and NDA [44] configurations in previous works, which may be summarised as follows. In the PDA (Figure 4), the co-located WECs configuration consisted of two main rows of WECs 
with a spacing of $198 \mathrm{~m}$ orientated towards the prevailing wave direction, and other rows of WECs at an angle of $45^{\circ}$ to face secondary wave directions and thus protect a larger wind farm area. The average wave height reduction in the farm $(H R F)$ was around $17 \%$, but its distribution throughout the wind farm $\left(H R A_{j}\right)$ showed important differences between the first and last rows of turbines (from 20.6\% to 8.1\%) (Figure 4). The NDA, with WECs deployed not only along the periphery but also within the wind farm, led to a more uniform wave reduction, with similar values of accessibility, and consequently availability, for all the wind turbines (Figure 4). In fact, the sampling variance of $H R A_{j}$ values was $32.14 \mathrm{~m}^{2}$ for the PDA and $13.41 \mathrm{~m}^{2}$ for the NDAs [46].
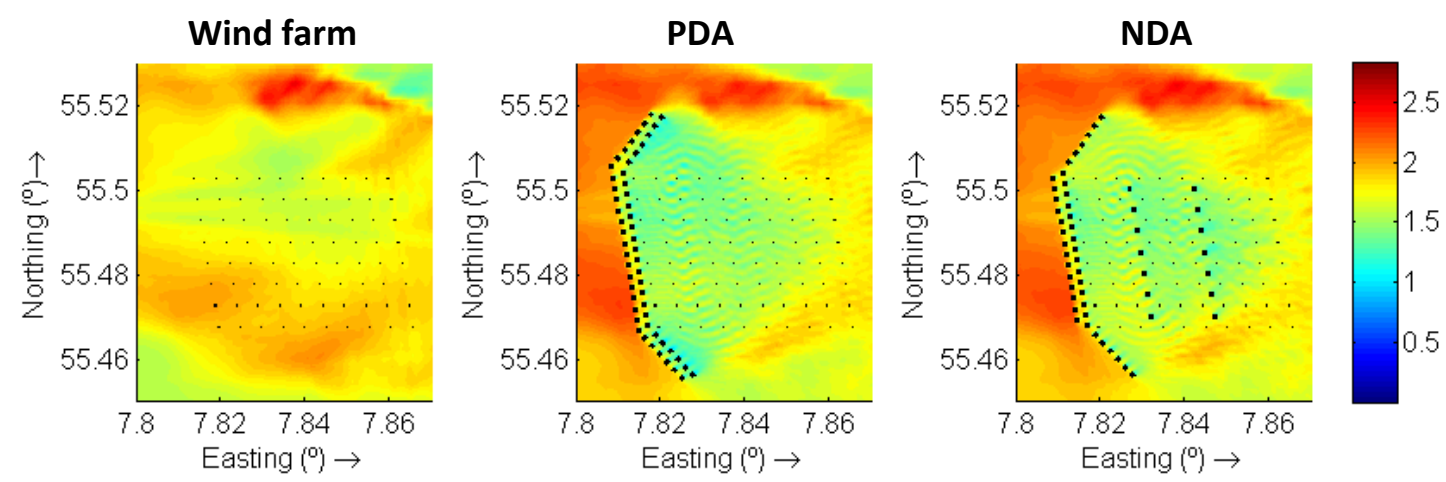

Figure 4. Comparative scheme of the wave climate between the baseline scenario (left), the PDA (middle) and NDA (right) co-located farms at Horns Rev. The colour scale represents the significant wave height [in $\mathrm{m}]$.

To define the UDA layouts for this comparative study a number of initial premises were adopted: (i) the total number of WECs was to be the same as in the previous studies with NDAs and PDAs at Horns Rev 1 (55 WECs); (ii) the barrier of WECs at the periphery of the farm orientated to the prevailing wave direction was maintained to achieve a sufficiently large initial shielding effect; and (iii) the rest of the devices were uniformly redistributed within the wind farm in order to avoid wave height regeneration. On this basis four UDA configurations were defined (Figure 5). 
PDA

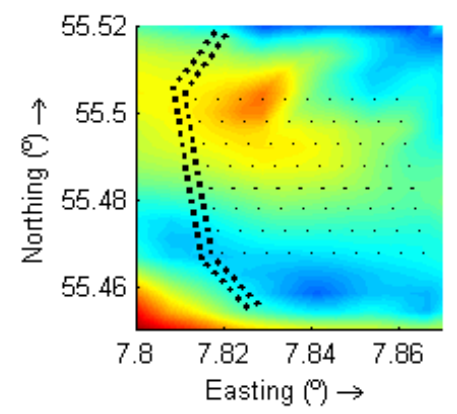

UDA-(ii)

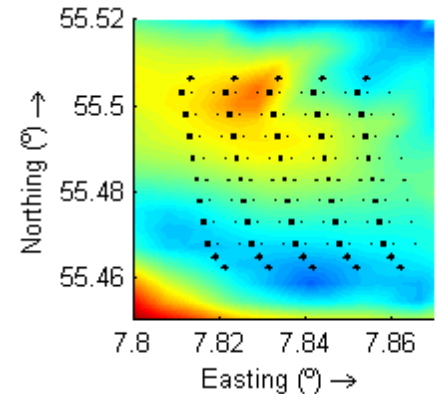

NDA
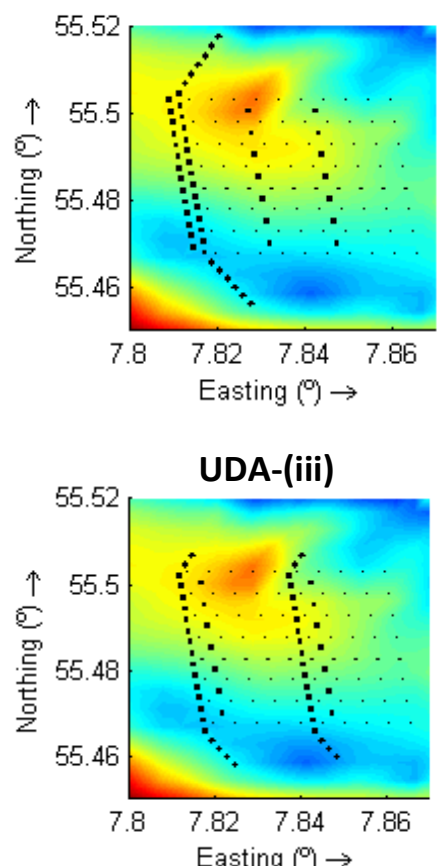

UDA-(i)
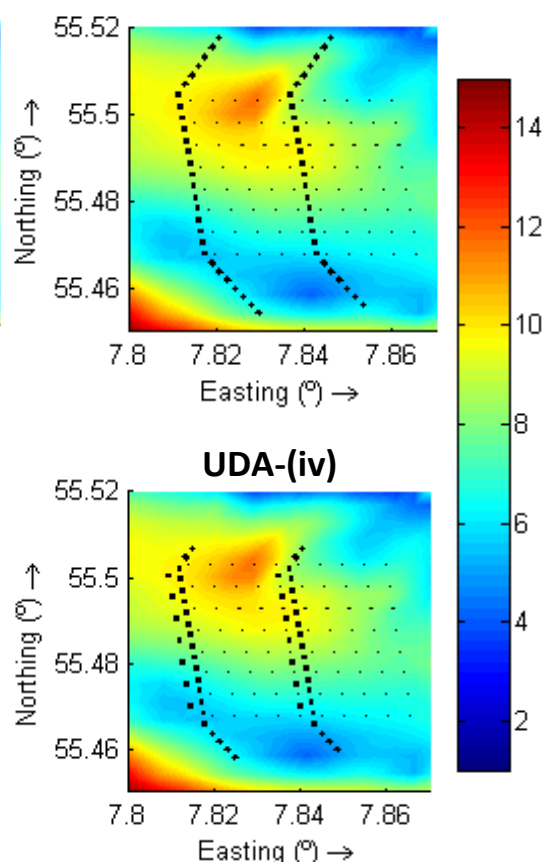

Figure 5. Co-located wave-wind farms: PDA, NDA and UDA configurations, from (i) to (iv).

\subsection{Wave propagation model}

The effectivity of the UDAs was assessed through the third-generation numerical wave model SWAN (Simulating WAves Nearshore), which was successfully used in previous work to model the propagation of waves, the absorption (transmission) of energy by the wave farm and also the impact of a wave farm on coastal processes [54, 56-61]. The evolution of the wave field is described by the action balance equation,

$$
\frac{\partial}{\partial t} N+\frac{\partial}{\partial x} c_{x} N+\frac{\partial}{\partial y} c_{y} N+\frac{\partial}{\partial \sigma} c_{\sigma} N \frac{\partial}{\partial \theta} c_{\theta} N=\frac{s_{t o t}}{\sigma},
$$

where $t$ is time (s), $c_{x}$ and $c_{y}$ are spatial velocities in the $x$ and $y$ components $\left(\mathrm{ms}^{-1}\right), c_{\theta}$ and $c_{\sigma}$ are rates of change of group velocity which describe the directional $(\theta)$ rate of turning and frequency $(\sigma)$ shifting due to changes in currents and water depth, $N$ is wave action density spectrum, and $S_{\text {tot }}$ is the energy density source terms which describe local changes to the wave spectrum. 
The model was implemented in the so-called nested mode in all cases, with two computational grids: (i) a coarse grid from offshore to the coast covering an area of $42 \times 32 \mathrm{~km}$ with a resolution of $70 \times 80 \mathrm{~m}$, and (ii) a fine ('nested') grid covering the study site $(9 \times 9 \mathrm{~km})$ with a resolution of $12 \times 20 \mathrm{~m}$. The bathymetric data from the European Marine Observation and Data Network (EMODnet) were interpolated onto this grid.

Both WECs and wind turbines were represented in the model by means of a transmission coefficient, whose value can theoretically vary from $0 \%$ (i.e., $100 \%$ of incident wave energy absorbed) to $100 \%$ (no energy absorbed) [19, 32, 54, 57-60, 62, 63]. Wave transmission through the WECs was implemented on the wave propagation model using the results of the laboratory tests carried out by Fernandez, Iglesias [52]. For its part, the transmission coefficient of the offshore wind turbines $\left(c_{t}\right)$ was calculated using

$$
\begin{gathered}
c_{t}=4\left(\frac{d}{H_{i}}\right) E\left[-E+\sqrt{E^{2}+\frac{H_{i}}{2 d}}\right] \text {, and } \\
E=\frac{C_{d}\left(\frac{b}{D_{p}+b}\right)}{\sqrt{1-\left(\frac{b}{D_{p}+b}\right)^{2}}}
\end{gathered}
$$

where $d$ is the water depth (m), $H_{i}$ is the incident significant wave height (m) and $E$ a non-dimensional coefficient that is calculated as a function of: the pile diameter $\left(D_{p}\right)$ in $\mathrm{m}$, the pile spacing $(b)$ in $\mathrm{m}$, and the drag coefficient of the piles $C_{d}$ (1.0 for a smooth pile) [64].

\subsection{Shielding effect and power output indicators}

The performance of the co-located UDA configurations was assessed by means of shielding effect and power output indicators defined ad hoc. First, the mean wave 
reduction throughout the wind farm was assessed through the significant wave Height Reduction within the Farm $(H R F)$,

$$
H R F=\frac{100}{n} \sum_{i=1}^{n} \frac{H_{s_{i}}-\left(H_{s, W E c}\right)_{i}}{H_{s_{i}}}
$$

where the index $i$ designates a generic turbine of the wind farm, $n$ is the total number of turbines, $H_{s i}$ is the significant wave height incident on the $i$-th turbine in the baseline scenario (without WECs), and $\left(H_{s, W E C}\right)_{i}$ is the significant wave height incident on the $i$ th turbine with co-located WECs.

Second, the variation of the wave height reduction within the farm was assessed by means of the significant wave Height Reduction along the $j$-th area of wind turbines,

$$
H R A_{j}=\frac{100}{m} \sum_{i=1}^{m} \frac{H_{s_{i}}-\left(H_{s, W E c}\right)_{i}}{H_{s_{i}}}
$$

where the index $i$ denotes a generic turbine of the $j$-th area of the wind farm, $m$ is the number of turbines in the $j$-th area, $H_{s i}$ is the significant height incident on the $i$-th turbine in the baseline scenario (without WECs) and $\left(H_{s, W E C}\right)_{i}$ is the significant height incident on the $i$-th turbine with co-located WECs. Each $j$-area corresponds to a northsouth (vertical in the figures) row of wind turbines, numbered from east to west.

Further, the global accessibility to the wind turbines was assessed by means of the percentage of time that the significant wave height was below the workboats limit (1.5 m). Finally, the percentage of wind turbines that are accessible (i.e., with a significant wave height in their vicinity below $1.5 \mathrm{~m}$ ) is given by

$$
A W T_{k}=\frac{\text { Accesible wind turbines }}{\text { Total number of wind turbines }} \times 100
$$


where $k$ is the percentage of time during which the wind turbines are accessible. This indicator was assessed for $k=100 \%, 90 \%, 80 \%, 70 \%$, and $60 \%$ or less.

The average power production of the co-located WECs is given by

$$
J_{\text {farm }}=\frac{1}{T} \sum_{i=1}^{n_{W}} \sum_{t=1}^{T}\left(J_{W, i}\right)_{t}
$$

where the index $i$ designates a generic WEC, $n_{W}$ is the total number of WECs, $t$ represents a point in time, $T$ the total number of time points considered and $J_{W, i}$ is the power production of the $i$-th WEC. The average wave power production per WEC in the farm can be calculated as

$$
J_{W E C}=\frac{J_{\text {farm }}}{n_{W}} .
$$

\subsection{Economic assessment}

The preliminary cost when starting up a wave farm involves engineering tasks and licences. Both are related to the installed power, the former ranges between 570,000€ and 2,300,000€ [65], and the latter can be estimated in Euros as $2.83 \%$ of the nominal power in Watts [66]. In this study, an average value of 1,500,000€ was assumed for the cost of preliminary studies, design and other engineering tasks to start up the proposed wave farms as stand-alone systems.

As for the capital cost, the initial investment at the Horns Rev 1 wind farm was $272 \mathrm{M} €$ [67]. In the case of the co-located WEC arrays proposed, the capital cost encompasses:

(i) WEC structure; (ii) power take-off system (PTO); (iii) mooring system; (iv) installation; and (v) electrical connection. The cost of the WECs depends on the material employed for the structure. In the case of the WaveCat, steel is the material selected, with a reference cost of 3,400 €/ton [68]. The displacement of the WaveCat 
model at a 1:30 scale is $360 \mathrm{~kg}$, and the weight of the structure is $100 \mathrm{~kg}$ [52]. The cost of the PTO can be estimated as $5,000 € / \mathrm{kW}$ [68]. As for the assembly, the most usual mooring system is CALM (Catenary Anchor Leg Mooring), whose cost can be calculated as a function of its weight $\left(W_{C A L M}\right), 300 € /$ ton [68]. Its weight (in N) can be estimated as [69]

$$
W_{C A L M}=9.81 L D_{C}^{2} K
$$

where $L$ is the total length of the catenary $(\mathrm{m}), D_{c}$ its diameter $(\mathrm{mm})$ and $K$ a constant with a value $0.02 \mathrm{~kg} /\left(\mathrm{m} \cdot \mathrm{mm}^{2}\right)$ for studless chain and $0.0219 \mathrm{~kg} /\left(\mathrm{m} \cdot \mathrm{mm}^{2}\right)$ for stud-link chain. The total length of the mooring line $(L)$ is usually estimated as 3-5 times the water depth [70-72]. In this work, the three-legged CALM system configuration [73] was selected and the length of the mooring line was assumed to be 4 times the water depth. Therefore, the total length of the catenary per WEC was $120 \mathrm{~m}$. As for the diameter a conservative value of $120 \mathrm{~mm}$ was considered [74-76]. Finally, the cost of the WECs installation and assembly has to be added - some 250,000€/MW [1, 77-79].

The electricity generated by the Horns Rev 1 wind farm $(600,000,000 \mathrm{kWh} /$ year [50]) is exported by a $63 \mathrm{~km}$ inter-array cable with MVAC $(30 \mathrm{kV})$ to the transformer $(75$ MVA), which elevates the power up to $110 \mathrm{kV}$ (HVAC) for the transmission to shore. Then, a $34 \mathrm{~km}$ export cable connects the transformer with the onshore station at Oksby (Esbjerg) [80]. The specific cost of the cable itself, $C_{\text {cable }}(€ / \mathrm{m})$, is a function of the voltage and the maximal current [81]:

$$
C_{\text {cable }}=\alpha+\beta e^{\left(\gamma I_{n} / 10^{5}\right)},
$$

where $\alpha, \beta$ and $\gamma$ are cost coefficients that depend on the operating voltage of the cable. For a $30 \mathrm{kV}$ cable, these coefficients are $54.37(€ / \mathrm{m}), 78.83(€ / \mathrm{m})$ and $234.34(1 / \mathrm{A})$, 
respectively. $I_{n}$ (A) is the maximal current in the medium voltage cable. The specific installation cost for MV (medium voltage) is assumed to be $380(€ / \mathrm{m})$ [81].

For MV/HV transformers from 50 to 800 MVA [82] the cost can be obtained as a function of the rated power of transformer, $A_{\mathrm{TR}}$ (MVA), as follows:

$$
C_{M V / H V}(k \epsilon)=44.568 A_{T R}^{0.7513}
$$

The cost of the offshore substation platform and its installation can be calculated as $0.0485 \mathrm{M€} / \mathrm{MW}$ [83]. Finally, the cost of the export HVAC cable can be calculated with the same equation as the inter-array cable (Eq. 10) but different coefficients: $\alpha=204.97$ $(€ / \mathrm{m}), \beta=47.42(€ / \mathrm{m})$ and $\gamma=333.587$ (1/A). The installation cost for HV cable is 750 $€ / \mathrm{m}[81]$.

Over the lifetime of the wind farm, the annual Operation and Maintenance (O\&M) costs are around $16 € / \mathrm{MWh}[67]$. Moreover, the balancing of the power production from the turbines is the responsibility of the farm owner. According to previous Danish experience, balancing brings in an equivalent cost of around $3 € / \mathrm{MWh}$ [67]. The O\&M cost of the WECs was estimated at $30 € / \mathrm{MWh}$ [84-87]. As for the wind turbines, the O\&M strategy at the Horns Rev wind farm is based on workboats, and their cost is in the range 10-28 €/MWh [23, 88-91].

Finally, the decommissioning cost at the end of the useful life of the installation ranges between 0.5 and $1 \%$ of the capital cost. In this study, a value of $0.75 \%$ was adopted. The cost-competitiveness of the co-located farm was assessed by means of the Levelised Cost of Energy ( $L C O E$ ), calculated as total cost divided by the total output (the value of the electricity generated) over the lifetime of the farm, both in present value: 


$$
L C O E=\frac{\sum_{t=0}^{n} C_{t} /(1+r)^{t}}{\sum_{t=0}^{n} o_{t} /(1+r)^{t}}
$$

where $C_{t}$ is the sum of all costs in year $t, O_{t}$ is the value of the output in year $t, \mathrm{n}$ is the lifetime of the farm in years $(t=0 \ldots n)$, and $r$ is the discount rate, which ranges between 5 and $15 \%$ in marine energy studies.

\section{Results and discussion}

\subsection{Wave propagation model}

The nearshore wave propagation model was validated with wave buoy data (Section 2.2). A good correlation was achieved between the simulated and observed time series (Figure 6), as shown by the values of the coefficient of determination $\left(R^{2}\right)$ and the Root Main Square Error (RMSE), 0.93 and $0.32 \mathrm{~m}$, respectively.

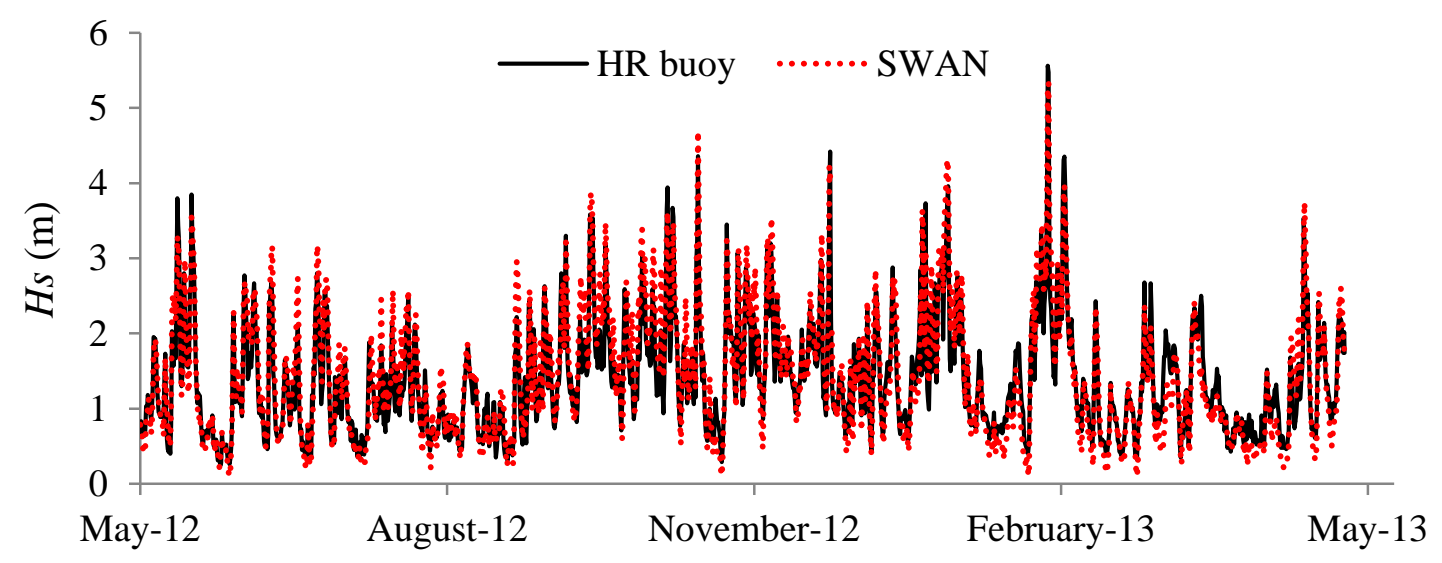

Figure 6. Time series simulated $\left(H_{s}, \mathrm{SWAN}\right)$ and measured $\left(H_{s}\right.$, buoy) significant wave height for the case study.

\subsection{Wave height reduction and accessibility}

First, the effectiveness of the four proposed co-located UDA of WECs was analysed in terms of wave height reduction for a representative sea climate (Section 2.2) (Table 2, Figure 7). 
Table 2. $H R A_{j}(\%)$ and $H R F(\%)$ values obtained with co-located WECs at Horns Rev 1 under a sea state with: $H_{s}=2 \mathrm{~m}, T_{p}=6 \mathrm{~s}$ and $\theta_{\text {wave }}=270^{\circ}$. The colour scale represents the significant wave weight, $H_{s}(\mathrm{~m})$.

\begin{tabular}{ccccccc}
\hline & \multicolumn{6}{c}{$H_{R A}(\%)$} \\
\hline \multirow{2}{*}{$j$-th area } & \multirow{2}{*}{ PDA } & \multirow{2}{*}{ NDA } & \multicolumn{4}{c}{ UDA } \\
\cline { 4 - 7 } & & & i & ii & iii & iv \\
\hline 1 & 31.27 & 29.00 & 26.73 & 24.47 & 22.20 & 19.93 \\
2 & 30.86 & 27.36 & 23.87 & 20.38 & 16.89 & 13.40 \\
3 & 28.14 & 23.12 & 18.10 & 13.07 & 8.05 & 3.03 \\
4 & 30.34 & 28.44 & 26.54 & 24.64 & 22.74 & 20.84 \\
5 & 28.80 & 28.41 & 28.01 & 27.61 & 27.22 & 26.82 \\
6 & 26.74 & 23.88 & 21.03 & 18.17 & 15.31 & 12.45 \\
7 & 22.21 & 23.28 & 24.36 & 25.43 & 26.51 & 27.58 \\
8 & 19.55 & 22.95 & 26.34 & 29.73 & 33.12 & 36.52 \\
9 & 18.21 & 21.62 & 25.02 & 28.42 & 31.82 & 35.22 \\
10 & 16.23 & 17.65 & 19.07 & 20.48 & 21.90 & 23.31 \\
\hline$H R F(\%)$ & 25.24 & 24.57 & 21.34 & 21.22 & 22.84 & 23.44 \\
\hline
\end{tabular}

$$
\begin{array}{rl|l|l|l|l}
H R A_{j}(\%) & 32 & 28 & 24 & 20 & 16
\end{array}
$$
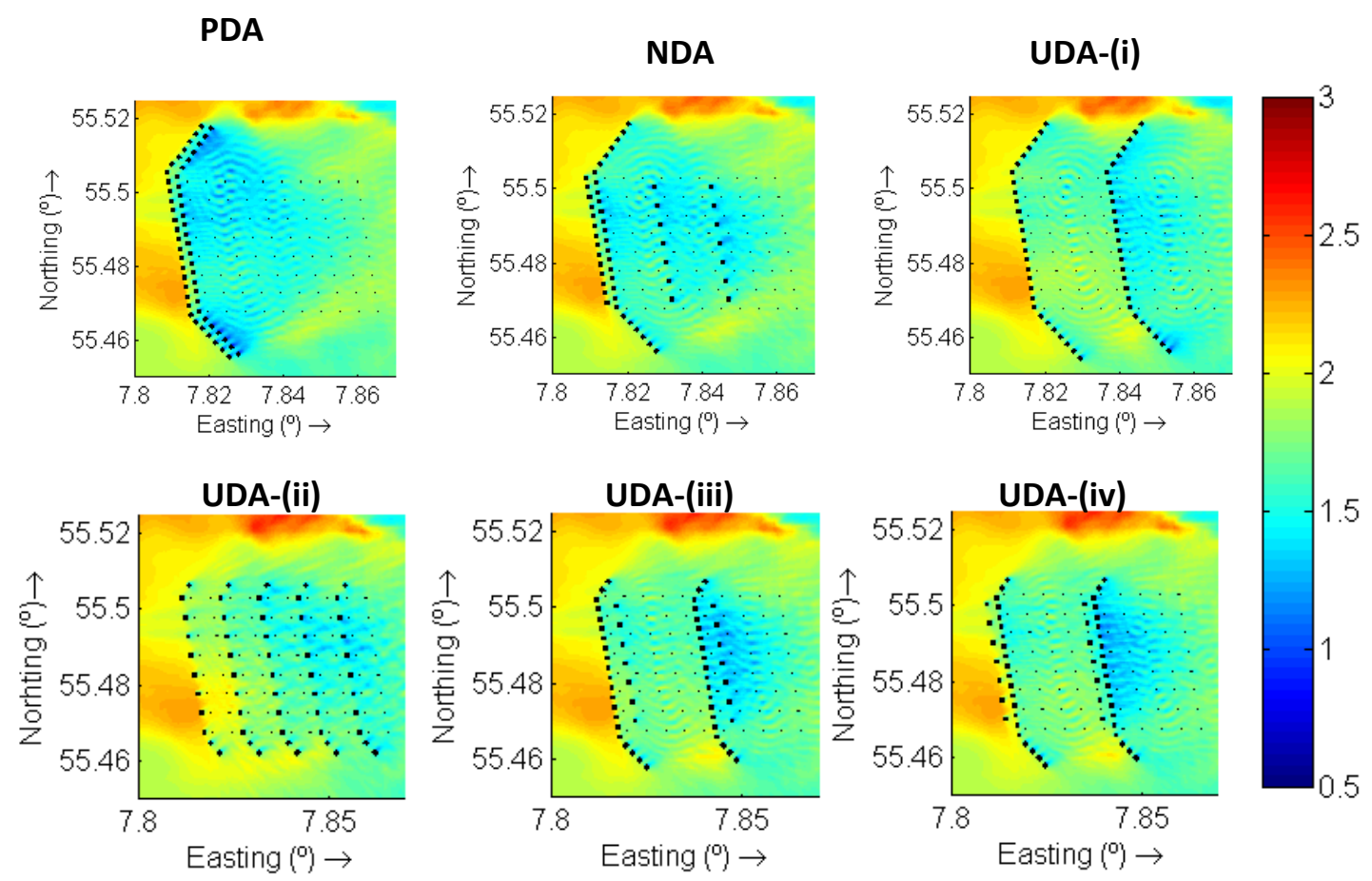

Figure 7. Comparison of the wave height reduction obtained with co-located WECs at Horns Rev 1 under a sea state with: $H_{s}=2 \mathrm{~m}, T_{p}=6 \mathrm{~s}$ and $\theta_{\text {wave }}=270^{\circ}$. The colour scale represents the significant wave weight, $H_{s}(\mathrm{~m})$. 
The UDA-(i) layout provided good wave height reduction with similar values to those obtained with NDAs but with the advantage of a greater protection in the last rows of wind turbines (Table 2, Figure 6). In exchange, the wave height reduction was lower along the third row of wind turbines (Table 2) due to the existence of a unique first barrier instead of the double barrier of the other configurations, which provided a larger initial reduction and, thus, retarded wave regeneration. In any case, the difference is not too great and, moreover, with the UDA configuration the interferences between WECs of consecutive rows disappeared, and therefore a larger power production may be expected.

In the case of the second configuration, UDA-(ii), waves were not well intercepted by the initial WECs barrier (Figure 6) due to the larger separation between devices needed to maintain the same number of WECs as in the other configurations; thus, the wave height reduction decreased in the first rows of wind turbines (Table 2), especially in the southwest part of the wind farm (Figure 6).

As for the configuration UDA-(iii), the wave height reduction in the entire farm $(H R F)$ was closer to the values obtained with the PDA and NDA configurations than with UDA-(i) and UDA-(ii). However, this layout was discarded in view of the large interferences between rows of WECs, not least in the case of the fourth (easternmost) row (Figure 7), which could be detrimental to power output.

Finally, the configuration UDA-(iv) achieved the greatest values of wave height reduction in the entire farm; however, the reduction was not as uniform as in the case of UDA-(i).

Based on the above results, the configurations UDA-(i) and (iv) were selected to continue the analysis with the entire wave dataset, extending from May 2012 to April 
2013. The UDA configurations achieved larger values of wave height reduction in the entire farm $(H R F)$ than the PDA and NDA configurations (Table 3); however, this did not translate into a better accessibility - the percentage of time when the wind turbines are accessible - since the reduced significant wave heights were still above the limit 1.5 $m$ threshold for workboat operation. Indeed, the NDA configuration achieved the best level of accessibility, followed by PDA. However, the accessibility values of the UDA configurations were not far behind, especially in the case of UDA-(iv). In all cases the accessibility was over $70 \%$ (Table 3 ) - a notable improvement with respect to the baseline, the standalone wind farm (approx. 60\%).

Table 3. HRF and accessibility values achieved considering the annual series of wave data with the PDA, NDA and UDA-(i),(iv) configurations of co-located WECs.

\begin{tabular}{ccccc}
\hline \multirow{2}{*}{ Parameter } & \multicolumn{4}{c}{ Configuration } \\
\cline { 2 - 5 } & PDA & NDA & UDA-(i) & UDA-(iv) \\
\hline$H R F(\%)$ & 17.01 & 17.93 & 18.27 & 18.46 \\
\hline Accessibility (\%) & 70.89 & 71.10 & 70.41 & 70.82 \\
\hline
\end{tabular}

Analysing the variation in wave height reduction moving away from the peripheral barrier of WECs is critical to establishing whether UDAs are able to mitigate the wave regeneration that occurred in the case of the PDA. On the basis of the $H R A_{j}$ values (Table 4), it is clear that the wave height reduction on the last rows of wind turbines was improved with the proposed layouts thanks to the WECs introduced between the fifth and sixth rows of wind turbines. On the downside, a smaller reduction was achieved in the western areas of the farm, albeit greater than the average reduction in the farm $(H R F)$. Therefore, UDAs presented a more uniform wave height reduction over the wind farm, particularly in the case of UDA-(i), which had the lowest variability in $H R A$. In fact, the analysis of accessibility to the wind turbines $\left(A W T_{k}\right)$ (Table 5) showed that the new configurations not only improved the global accessibility nearly as much as PDAs and NDAs (an improvement of approx. 10\% with respect to the baseline 
scenario) but also achieved a more uniform distribution of wave height, leading to similar values of accessibility for all the wind turbines.

Table 4. $H R A_{j}$ values based on the annual series of wave data with the PDA, NDA and UDA(i),(ii) configurations of co-located WECs.

\begin{tabular}{ccccc}
\hline \multirow{2}{*}{$j$-th area } & \multicolumn{4}{c}{$H R A_{j}(\%)$} \\
\cline { 2 - 5 } & PDA & NDA & UDA-(i) & UDA-(iv) \\
\hline 1 & 30.62 & 28.27 & 21.14 & 23.45 \\
2 & 26.28 & 23.29 & 17.12 & 17.23 \\
3 & 21.53 & 20.5 & 15.8 & 15.65 \\
4 & 19.98 & 20.38 & 16.16 & 16.93 \\
5 & 17.44 & 18.52 & 17.59 & 19.97 \\
6 & 15.02 & 16.34 & 26.80 & 28.03 \\
7 & 11.68 & 17.07 & 21.22 & 21.40 \\
8 & 10.18 & 12.8 & 18.28 & 16.04 \\
9 & 9.25 & 11.49 & 15.79 & 14.54 \\
10 & 8.16 & 8.67 & 12.87 & 11.37 \\
\hline \multicolumn{5}{c}{} \\
\end{tabular}

Table 5. $A W T_{k}(\%)$ values for the standalone system (Wind Farm, WF) and for the colocated farms with PDA, NDA or UDA configurations.

\begin{tabular}{cccccc}
\hline & \multicolumn{5}{c}{ Configuration } \\
\cline { 2 - 6 }$k(\%)$ & WF & PDA & NDA & UDA-(i) & UDA-(iv) \\
\hline 100 & 0 & 0 & 0 & 0 & 0 \\
\hline $90-100$ & 0 & 0 & 0 & 0 & 0 \\
\hline $80-90$ & 0 & 10 & 3.75 & 2.5 & 5 \\
\hline $70-80$ & 0 & 46.25 & 55 & 45 & 47.5 \\
\hline $60-70$ & 45 & 43.75 & 41.25 & 52.5 & 47.5 \\
\hline$\leq 60$ & 55 & 0 & 0 & 0 & 0 \\
\hline
\end{tabular}

\subsection{Power production}

In addition to the shielding effect of the co-located WECs discussed in the previous section, their power production is of interest per se. In the case of the PDA configuration the results were generally good; nevertheless, the WECs deployed on the second row of the peripheral barrier saw their output reduced due to the wave power 
deficits in the wakes of the WECs on the first row [45]. This problem was in part overcome with the NDA configuration, which reduced the interference between devices by intercalating some of the WECs within the wind turbines, at a distance from the peripheral barrier - leading to an increase of the average power production per WEC $\left(J_{W E C}\right)$ of approx. 1\%. The new configurations, UDA-(i) and (iv), achieved even better results, with increases of approx. $3 \%$ and $2 \%$ (Table 6). The explanation is straightforward. Whereas in the case of the NDA configuration only certain WECs were removed from the double peripheral barrier and distributed amid the wind turbines, in the UDA configurations a greater number of devices were relocated, especially in the case of UDA-(i), in which there was no double barrier of WECs - the entire second row was deployed after the fifth row of wind turbines, where wave heights were beginning to recover. In the case of UDA-(iv), the power production increased in spite of the double barrier of WECs since the spacing between WECs was greater than in the case of the PDA and NDA configurations, leading to reduced interference between WECs of the first and second rows.

Table 6 . Average power production $\left(J_{\text {farm }}\right)$ generated by the co-located WECs and average power production per WEC $\left(J_{W E C}\right)$ for the PDA, NDA and UDA configurations.

\begin{tabular}{ccccc}
\hline Configuration & PDA & NDA & UDA-(i) & UDA-(iv) \\
\hline$J_{\text {farm }}(\mathrm{MW})$ & 30.6 & 31.0 & 31.6 & 31.3 \\
\hline$J_{W E C}(\mathrm{~kW})$ & 557.1 & 563.5 & 574.1 & 568.2 \\
\hline
\end{tabular}

\subsection{Economic analysis}

The costs of the four co-located arrays as independent systems (without considering the synergies with the wind farm) are summarised in Table 7. Some of them were the same for the four configurations, such as the costs of licenses and permitting, which are dependent on installed power, and the cost of the WECs and the mooring system. Among the different categories, the WECs had the highest weight in the total cost. This 
is expected to reduce as the technology develops and economies of scale are realised.

The O\&M cost was certainly not negligible - it is an ongoing expenditure which represents a sizeable amount at the end of the service life of the farm.

Table 7. Costs involved in the four co-located farms analysed.

\begin{tabular}{|c|c|c|c|c|c|c|c|}
\hline \multicolumn{4}{|c|}{ Category } & PDA & NDA & UDA-(i) & UDA-(iv) \\
\hline \multirow{3}{*}{$\begin{array}{l}\text { Preliminary } \\
\text { costs }\end{array}$} & \multicolumn{3}{|c|}{ Engineering $(€)$} & $1,500,000$ & $1,500,000$ & $1,500,000$ & $1,500,000$ \\
\hline & \multicolumn{3}{|c|}{ Licenses $(€)$} & $1,867,800$ & $1,867,800$ & $1,867,800$ & $1,867,800$ \\
\hline & & & TOTAL $(€)$ & $3,367,800$ & $3,367,800$ & $3,367,800$ & $3,367,800$ \\
\hline \multirow{9}{*}{ Capital cost } & \multirow{4}{*}{ WECs } & WECs structure $(€)$ & & $504,900,000$ & $504,900,000$ & $504,900,000$ & $504,900,000$ \\
\hline & & PTO $(€)$ & & $330,000,000$ & $330,000,000$ & $330,000,000$ & $330,000,000$ \\
\hline & & Mooring $(€)$ & & 624,413 & 624,413 & 624,413 & 624,413 \\
\hline & & Installation $(€)$ & & $16,500,000$ & $16,500,000$ & $16,500,000$ & $16,500,000$ \\
\hline & \multirow{5}{*}{$\begin{array}{l}\text { Electrical } \\
\text { installation }\end{array}$} & \multirow{2}{*}{ Inter-array cable } & Length (km) & 10.23 & 14.52 & 12.09 & 14.12 \\
\hline & & & Cost $(€)$ & $7,169,068$ & $8,988,270$ & $8,476,166$ & $8,421,566$ \\
\hline & & Offshore station $(€)$ & & $4,343,238$ & $4,343,238$ & $4,343,238$ & $4,343,238$ \\
\hline & & \multirow[t]{2}{*}{ Export cable $(€)$} & & $37,589,360$ & $37,589,360$ & $37,589,360$ & $37,589,360$ \\
\hline & & & TOTAL & $901,126,079$ & $902,945,281$ & $902,433,177$ & $902,378,577$ \\
\hline \multicolumn{4}{|c|}{ O\&M cost (€/year) } & $3,860,514$ & $3,904,992$ & $3,978,576$ & $3,937,626$ \\
\hline \multicolumn{4}{|c|}{ Decommissioning $(€)$} & $6,758,446$ & $6,772,090$ & $6,768,249$ & $6,767,839$ \\
\hline
\end{tabular}

It is clear that through the combination between wind turbines and co-located WECs important savings can be obtained. First, the engineering cost reduced to $570,000 €$, since the site had already been studied and characterised, and part of the elements to be designed could be shared, e.g. the electrical grid. With regard to the capital cost, the largest savings were achieved in the electrical connection, since the offshore station and the export cable could be the same for both installations. The capital cost reduction was approx. $4.7 \%$. With regard to the O\&M costs, some of the costs involved could be shared by the wave and wind elements of a co-located farm in order to achieve cost reductions. This is not the case, however, of the cost of equipment replacement, which represented the largest proportional cost of offshore farms. Nevertheless, some savings can still be made: the scheduled maintenance of wave and wind energy could be carried 
out at the same time or in a continuous period of time, reducing the cost associated with the transport of maintenance staff and the boarding of personnel onto offshore structures (5.34 k€/MW) [83]. The same applies to the labour cost, which covers the cost of O\&M staff - its access (8.01 k€/MW) and labour (7.12 k€/MW) [83]; this staff would typically be stationed on the project full time, and so could be shared for both installations. The increase in the accessibility to the wind turbines (Table 3) also decreased O\&M costs by reducing downtime due to delays in unexpected repairs. Improving the weather windows for O\&M might bring about a saving of $25 \%$, which would involve an overall improvement in the project cost of energy of $2.3 \%$ [92]. On these grounds the O\&M cost of the co-located WECs reduced between $28.3 \%$ and $29.2 \%$ for the four arrays analysed.

The above considerations were taken into account in calculating the $L C O E$ values of the four co-located farms analysed (Table 8). Among the four layouts, UDA-(i) stood out as the most convenient configuration of co-located WECs. The LCOE difference with the other configurations may seem not so relevant at first, but considering the total annual production ( $730 \mathrm{GWh}$ on average), the difference does amount to approximately $900,000 €$ per annum - certainly not negligible.

Table 8. $L C O E$ values for the four co-located farms analysed.

\begin{tabular}{cc}
\hline Co-located layout & $L C O E(€ / \mathrm{MWh})$ \\
\hline PDA & 200.64 \\
NDA & 199.96 \\
UDA-(i) & 199.41 \\
UDA-(iv) & 199.72 \\
\hline
\end{tabular}

\section{Conclusions}

Operation and maintenance is a particularly challenging aspect of offshore wind energy. These labours can be delayed by difficult sea conditions - in particular, large wave heights - leading to downtime and, consequently, increased costs. This can be offset in 
part by combining offshore wind and wave energy systems, which can improve the accessibility to the wind turbines by reducing the wave heights within the farm and, in addition, generate additional revenue from their power production. The actual results depend on the configuration of the co-located farm. Previous works showed that peripherally distributed arrays (PDAs) achieve good results in terms of wave height reduction within the farm and average accessibility. However, important differences between the accessibility to the wind turbines located directly in the lee of the peripheral WEC barrier and the other turbines in the farm were found. As an alternative, nonuniformly distributed arrays (NDAs) were investigated. By intercalating some of the WECs amid the wind turbines, NDA configurations were found to counter the wave regeneration in the lee of the peripheral barrier of WECs; however, these configurations present a number of problems as a result of the non-uniform layout, which hinders the installation, increases certain costs (e.g. the submarine cable) and hampers the navigation of the workboats between the wind turbines.

On this basis, the objective of this paper was to analyse whether a different type of configuration for the co-located WECs, uniformly distributed arrays (UDAs), can avoid some of these problems and at the same time lead to a more uniform wave height reduction throughout the farm. For this purpose a case study was carried out at the Horns Rev 1 wind farm. In a preliminary study, four UDA layouts were considered, and the two best-performing were retained for a more detailed analysis, alongside PDA and NDA configurations. A dataset of wave parameters covering an entire year was used in conjunction with a third-generation spectral wave model (SWAN). It was found that the UDAs achieved larger values of wave height reduction over the entire farm than the PDA and NDA, mitigating the wave regeneration that occurred in certain sections of the farm with the PDA configuration. Moreover, increases of the power production per 
WEC $\left(J_{W E C}\right)$ of approx. 3\% were found. Finally, the levelised cost of energy of the colocated farms was calculated by translating all these results into monetary terms, in combination with other synergies such as common strategies and shared elements. UDA co-located wind and wave energy farms led to better results than the PDA and NDA configurations. More specifically, of the four UDA configurations analysed, UDA-(i) stood up as the most convenient array of co-located WECs, with savings of up to $900,000 €$ per year.

The LCOE values of the co-located farms were found to be in line with those of offshore wind farms currently in operation [93-95], with the advantage of a more sustainable use of the marine space (two renewables at the same site) and smoothed power output due to the co-located WECs [40]. Moreover, when these values are compared with those of standalone wave farms, significant reductions in the LCOE are apparent (around 70\%). In conclusion, the co-location of WECs and offshore wind turbines constitutes an opportunity for wave energy to become more cost competitive, attract investment and, thus, accelerate its development.

\section{Acknowledgment}

This work was carried out in the framework of the Atlantic Power Cluster project (Atlantic Area Project nr. 2011-1/151, ATLANTICPOWER), funded by the Atlantic Area Operational Transnational Programme as part of the European Regional and Development Fund (ERDF). Astariz has been supported by FPU grant 13/ 03821 of the Spanish Ministry of Education, Culture and Sport. The authors are grateful to the Horns Rev wind farm for the resource data of the site; and to the European Marine Observation and Data Network (EMODnet) for the bathymetric data of the North Sea. 


\section{References}

[1] BWEA. Marine Renewable Energy-State of the industry report. 2009.

[2] Maisondieu C, Healy M. The impact of the MARINET initiative on the development of Marine Renewable Energy. International Journal of Marine Energy. 2015;12:77-86.

[3] Iglesias G, Carballo R. Wave energy potential along the Death Coast (Spain). Energy. 2009;34(11):1963-75.

[4] Iglesias G, Carballo R. Offshore and inshore wave energy assessment: Asturias (N Spain). Energy. 2010;35(5):1964-72.

[5] Iglesias G, Carballo R. Wave power for La Isla Bonita. Energy. 2010;35(12):5013-21.

[6] Rusu E, Onea F. Evaluation of the wind and wave energy along the Caspian Sea. Energy. 2013;50(0):1-14.

[7] Iglesias G, Carballo R. Choosing the site for the first wave farm in a region: A case study in the Galician Southwest (Spain). Energy. 2011;36(9):5525-31.

[8] Mirzaei A, Tangang F, Juneng L. Wave energy potential along the east coast of Peninsular Malaysia. Energy. 2014;68(0):722-34.

[9] Association ETEWE. The European offshore wind industry -key trends and statistics 2013. Available at:

http://www.ewea.org/fileadmin/files/library/publications/statistics/European offshore statistics 2013.pdf. 2014.

[10] Sun X, Huang D, Wu G. The current state of offshore wind energy technology development. Energy. 2012;41:298-312.

[11] Esteban MD, Diez JJ, López JS, NegroV. Why offshore wind energy? Renewable Energy. 2011; 36(2): 444-450.

[12] Vazquez A, Iglesias G. Grid parity in tidal stream energy projects: An assessment of financial, technological and economic LCOE input parameters. Technological Forecasting and Social Change. 2016;104:89-101.

[13] Vazquez A, Iglesias G. LCOE (levelised cost of energy) mapping: A new geospatial tool for tidal stream energy. Energy. 2015;91:192-201.

[14] Waters S, Aggidis G. Tidal range technologies and state of the art in review. Renewable and Sustainable Energy Reviews. 2016;59:514-29.

[15] Falcão AFdO. Wave energy utilization: A review of the technologies. Renewable and Sustainable Energy Reviews. 2010;14(3):899-918.

[16] Clément A, McCullen P, Falcão A, Fiorentino A, Gardner F, Hammarlund K, et al. Wave energy in Europe: current status and perspectives. Renewable and Sustainable Energy Reviews. 2002;6(5):405-31.

[17] Bucher R, Jeffrey H, Bryden IG, Harrison GP. Creation of investor confidence: The toplevel drivers for reaching maturity in marine energy. Renewable Energy. 2016;88:120-9.

[18] Ramos V, Iglesias G. Wind Power Viability on a Small Island. International Journal of Green Energy. 2014;11(7):20. 
[19] Veigas M, Iglesias G. Potentials of a hybrid offshore farm for the island of Fuerteventura. Energy Conversion and Management. 2014;86(0):300-8.

[20] Veigas M, Carballo R, Iglesias G. Wave and offshore wind energy on an island. Energy for Sustainable Development. 2014; 22: 57-65.

[21] Veigas M, Iglesias G. Wave and offshore wind potential for the island of Tenerife. Energy Conversion and Management. 2013;76(0):738-45.

[22] Blanco MI. The economics of wind energy. Renewable and Sustainable Energy Reviews. 2009;13(6-7):1372-82.

[23] Esteban MD, Lopez-Gutierrez JS, Diez JJ, Negro V. Methodology for the design of offshore wind farms. Journal of Coastal Research. 2011; 64: 496.

[24] Esteban MD, Diez JJ, López JS, Negros V. Integral management applied to offshore wind farms. Journal of Coastal Research. 2009; (0): 1204-1208.

[25] Bussel WAAMBaGJWv. The impact of different means of transport on the operation and maintenance strategy for offshore wind farms. Section Wind Energy, Faculty Civil Engineering and Geosciences, Delft University of Technology, The Netherlands 2002.

[26] Daubney K. Getting technicians to far-shore wind farms. In: OFFSHORE W, editor.2013.

[27] Bussel GJWv, Zaaijer MB. Reliability, Availability and Maintenance aspects of large-scale offshore wind farms, a concepts study. Conference Reliability, Availability and Maintenance aspects of large-scale offshore wind farms, a concepts study., Brussels, Belgium.

[28] Perveen R, Kishor N, Mohanty SR. Off-shore wind farm development: Present status and challenges. Renewable and Sustainable Energy Reviews. 2014;29(0):780-92.

[29] Scheu M, Matha D, Hofmann M, Muskulus M. Maintenance Strategies for Large Offshore Wind Farms. Energy Procedia. 2012;24(0):281-8.

[30] Makridis C. Offshore wind power resource availability and prospects: A global approach. Environmental Science \& Policy. 2013;33(0):28-40.

[31] Astariz S, Perez-Collazo C, Abanades J, Iglesias G. Towards the optimal design of a colocated wind-wave farm. Energy. 2015;84(0):15-24.

[32] Veigas M, Ramos V, Iglesias G. A wave farm for an island: Detailed effects on the nearshore wave climate. Energy. 2014;69(0):801-12.

[33] Abanades J, Greaves D, Iglesias G. Coastal defence through wave farms. Coastal Engineering. 2014;91(0):299-307.

[34] Negro V, López-Gutiérrez JS, Esteban MD, Matutano C. Uncertainties in the design of support structures and foundations for offshore wind turbines. Renewable energy. 2014; 63: 125-132.

[35] Carlos. Pérez-Collazo MMJ, Hannah. Buckland , Julia. Fernández-Chozas. Synergies for a wave-wind energy concept. Conference Synergies for a wave-wind energy concept, Vienna.

[36] EU-OEA. Oceans of Energy. European Ocean Energy Roadmap 2010-2050. Bietlot, Belgium2010. 
[37] J. Moccia AA, J. Wilkes, C. Kjaer, and R. Gruet. Pure Power. Wind energy targets for 2020 and 2030. European Wind Energy Association. Brussels, Belgium2011.

[38] Azzellino A, Ferrante V, Kofoed JP, Lanfredi C, \& Vicinanza, D. Optimal siting of offshore wind-power combined with wave energy through a marine spatial planning approach. International Journal of Marine Energy. 2013, 3: 11-25.

[39] Astariz S, Iglesias G. Co-located wave-wind farms: Economic assessment as a function of layout. Renewable Energy. 2015;In Press.

[40] Astariz S, Iglesias G. Output power smoothing and reduced downtime period by combined wind and wave energy farms. Energy. 2016;97:69-81.

[41] Fusco F, Nolan G, Ringwood JV. Variability reduction through optimal combination of wind/wave resources - An Irish case study. Energy. 2010;35(1):314-25.

[42] Esteban MD, López-Gutiérrez JS, Negro V, Matutano C, García-Flores FM, Millán MÁ. Offshore wind foundation design: Some key issues. Journal of Energy Resources Technology. 2015; 137(5): 051211.

[43] Pérez-Collazo C, Greaves D, Iglesias G. A review of combined wave and offshore wind energy. Renewable and Sustainable Energy Reviews. 2015;42(0):141-53.

[44] Astariz S, Abanades J, Perez-Collazo C, Iglesias G. Improving wind farm accessibility for operation \& maintenance through a co-located wave farm: Influence of layout and wave climate. Energy Conversion and Management. 2015;95(0):229-41.

[45] Astariz S, Perez-Collazo C, Abanades J, Iglesias G. Co-located wind-wave farm synergies (Operation \& Maintenance): A case study. Energy Conversion and Management. 2015;91(0):63-75.

[46] Astariz S, Iglesias G. Accessibility for operation and maintenance tasks in co-located wind and wave energy farms with non-uniformly distributed arrays. Energy Conversion and Management. 2015;106:1219-29.

[47] Marsh G. Deep offshore O\&amp;M: accessing all areas. Renewable Energy Focus. 2013;14(1):25-30.

[48] Frank H, Rathmann O, Mortensen N, Landberg L. The Numerical Wind Atlas - the KAMM/WAsP Method. Roskilde, Denmark: Riso. 2001.

[49] Miljødata E. Case studies calculating wind farm production-Main Report. Denmark: Energi- og Miljødata. 2002.

[50] Neill SP, Hashemi MR. Wave power variability over the northwest European shelf seas. Applied energy. 2013; 106: 31-46.

[51] Iglesias G, Fernández H, Carballo R, Castro A, Taveira-Pinto F. The WaveCat@ Development of a new Wave Energy Converter Conference The WaveCat $\odot$ - Development of a new Wave Energy Converter Linkoping, Sweden.

[52] Fernandez H, Iglesias G, Carballo R, Castro A, Fraguela JA, Taveira-Pinto F, et al. The new wave energy converter WaveCat: Concept and laboratory tests. Marine Structures.

2012;29(1):58-70.

[53] Barrero A. España apuesta por las olas. Energías Renovables, especial Energías del Mar. 2011;106:10. 
[54] Carballo R, Iglesias G. Wave farm impact based on realistic wave-WEC interaction. Energy. 2013;51(0):216-29.

[55] Astariz S, Perez-Collazo C, Abanades J, Iglesias G. Towards the optimal design of a colocated wind-wave farm. Energy. 2015;In Press.

[56] Palha A, Mendes L, Fortes CJ, Brito-Melo A, Sarmento A. The impact of wave energy farms in the shoreline wave climate: Portuguese pilot zone case study using Pelamis energy wave devices. Renewable Energy. 2010;35(1):62-77.

[57] Smith HCM, Pearce C, Millar DL. Further analysis of change in nearshore wave climate due to an offshore wave farm: An enhanced case study for the Wave Hub site. Renewable Energy. 2012;40(1):51-64.

[58] Millar DL, Smith HCM, Reeve DE. Modelling analysis of the sensitivity of shoreline change to a wave farm. Ocean Engineering. 2007;34(5-6):884-901.

[59] Iglesias G, Carballo R. Wave farm impact: The role of farm-to-coast distance. Renewable Energy. 2014;69(0):375-85.

[60] Abanades J, Greaves D, Iglesias G. Wave farm impact on the beach profile: A case study. Coastal Engineering. 2014;86(0):36-44.

[61] El Marjani A, Castro Ruiz F, Rodriguez MA, Parra Santos MT. Numerical modelling in wave energy conversion systems. Energy. 2008;33(8):1246-53.

[62] Ponce de Leon S, Bettencourt, J.H., Kjerstad, N. Simulation of Irregular Waves in an Offshore Wind Farm with a Spectral Wave Model. Continental Shelf Res. 2011;31:17.

[63] ETSU. Potential effects of offshore wind developments on coastal processes. ETSU W/35/00596/00/REP. In: METOC PbAa, editor. http://www.offshorewindenergy.org/reports/report_002.pdf2002.

[64] Hayashi T, Hattori, M., Kano, T., Shirai, M. Hydraulic Research on the Closely Spaced Pile Breakwater. Coastal Engineering. 1966;50:12.

[65] Castaño M. Sistema de monitorización y supervisión de una boya para generación de energía undimotriz. In: Cataluña UPd, editor. Spain: Universidad Politécnica de Cataluña; 2011.

[66] Li Y, Lence BJ, Calisal SM. An integrated model for estimating energy cost of a tidal current turbine farm. Energy Conversion and Management. 2011;52(3):1677-87.

[67] J.K. Lemming PEM, N.E. Clausen. Offshore Wind Power Experiences, Potential and Key Issues for Deployment. Roskilde: Danmarks Tekniske Universitet, Ris $\emptyset$ Nationallaboratoriet for Bæredygtig Energi. (Denmark. Forskningscenter Risoe. Risoe-R; No. 1673(EN)). 2009. p. 053112 .

[68] Julia Fernández-Chozas JPK, Niels Ejner Helstrup Jensen. User guide - The COE Calculation. Tool for Wave Energy Converters ISSN 1901-726X DCE Technical Report No 161. 2014.

[69] Vicinay Cemvisa V. 2012. Available at: http://www.vicinaycemvisa.com/ [3/3/2012]

[70] Atkins. A parametric model of costs for the wave energy technology. In: 1992. EINWPaG, editor.1992.

[71] Veatch N. The commercial perspectives for the wave energy. In: ETSU T/06/00209/REP. DTI Programmes of Sustainable Energy DTI / Pub URN 01/1011, editor.2001. 
[72] RE Harris LJ, J Wolfram. Mooring systems for wave energy converters: a review of the design problems and options. Congress VII World of Renewable Energies. Denver, EE.UU.2004.

[73] Pecher A, Foglia A, Kofoed JP. Comparison and Sensitivity Investigations of a CALM and SALM Type Mooring System for Wave Energy Converters. Marine Science and Engineering. 2014;2:93-122.

[74] Kirrane P, Fabricius P, Morvan R. Development of an Efficient Design Technique for the Optimisation of Mooring Systems for Wave Energy Arrays. Industry-Led Award, Final Report Marine Research Sub-Programme (NDP 2007-13) Series. 2010.

[75] Ambühl S, Sterndorff M, Sørensen JD. Extrapolation of extreme response for different mooring line systems of floating wave energy converters. International Journal of Marine Energy. 2014; In Press.

[76] Pecher A, Foglia A, Kofoed JP. Comparison and Sensitivity Investigations of a CALM and SALM Type Mooring System for Wave Energy Converters. Journal of Marine Science and Engineering. 2014;2:30.

[77] Guanche R, de Andrés AD, Simal PD, Vidal C, Losada IJ. Uncertainty analysis of wave energy farms financial indicators. Renewable Energy. 2014;68(0):570-80.

[78] O'Connor M, Lewis T, Dalton G. Operational expenditure costs for wave energy projects and impacts on financial returns. Renewable Energy. 2013;50(0):1119-31.

[79] Trust C. Capital, oerating and maintenance costs. 2006.

[80] 4COffshore. Horns Rev 1 Offhire Wind Farm. Available at: http://www.4coffshore.com/windfarms/horns-rev-1-denmark-dk03.html. 2016.

[81] Dicorato M, Forte G, Pisani M, Trovato M. Guidelines for assessment of investment cost for offshore wind generation. Renewable Energy. 2011;36(8):2043-51.

[82] LP L. Economic comparison of HVAC and HVDC solutions for large offshore wind farms under special consideration of reliability. Masters' thesis, Royal Institute of Technology, Stockholm; 2005. 2005.

[83] Norway TrCo. Offshore Wind Asessment For Norway. Douglas Westwood. 2010.

[84] R Bedard MP, G Hagerman. American Ocean Energy Status. Conference American Ocean Energy Status.

[85] O Siddiqui RB. Feasibility assessment of offshore wave and tidal current power production: a collaborative public/private partnership. IEEE Power Engineering, 2005. Piscataway, NJ, USA2005.

[86] Wave O. Value of Wave Power. Oregan Wave Energy Utility Trust, 20102010.

[87] Dunnett D, Wallace JS. Electricity generation from wave power in Canada. Renewable Energy. 2009;34(1):179-95.

[88] Milborrow D. Breaking down the cost of wind turbine maintenance. In: WINDPOWER, editor.2010.

[89] Waveplam. Wave energy: a guide for investors and politicians. In: Waveplam EPoIE, editor.2010. 
[90] British Wind Energy Association B. Reform of the Renewables Obligation (Preliminary consultation). Joint response by BWEA and REA. 2006.

[91] Intermoney-AEE. Análisis y Diagnóstico de la Situación de la Energía Eólica en España. Commissioned by Asociación Empresarial Eólica, Madrid, Spain Internal document; 2006. 2006.

[92] Enterprise S. Innnovation in Offshore Wind. Installation, Operation \& Maintenance. 2012.

[93] Allan G, Gilmartin M, McGregor P, Swales K. Levelised costs of Wave and Tidal energy in the UK: Cost competitiveness and the importance of "banded" Renewables Obligation Certificates. Energy Policy. 2011;39(1):23-39.

[94] EIA. annual Energy Outlook. In: Energy. USEIAUSDo, editor. Washington, DC 205852014.

[95] MacDonald M. UK Electricity Generation Costs Update. In: DECC, editor. London2010. 